\title{
Morfologia social e contextualização topográfica: a micro-história de Edoardo Grendi
}

\author{
Social Morphology and Topographical \\ Contextualization: the Microhistory of Edoardo Grendi
}

Matteo Giuli*

\section{Resumo}

A micro-história italiana é geralmente conhecida como o produto dos ensinamentos de Giovanni Levi e Carlo Ginzburg, considerados seus pais fundadores. A figura de Edoardo Grendi é menos conhecida, sobretudo fora da Europa, e seu papel na formulação da proposta micro-histórica é até subestimado, apesar de ele ter sido, talvez, seu mais precoce teorizador. Graças à sua atenção aos problemas historiográficos internacionais e ao seu interesse pelas ciências sociais, Grendi se destacou como uma figura não convencional no contexto acadêmico do seu tempo, provocando um debate fecundo e também polêmico. É possível colocar sua lição, portanto, no mesmo plano das de Levi e Ginzburg, independentemente da separação entre micro-história social e cultural, no âmbito da qual elas foram inseridas. Esses três historiadores, de fato, protagonizaram a mesma batalha, que visava esclarecer as possibilidades e os limites do conhecimento do passado. Palavras-chave: morfologia; contextualização; micro-história.

\section{Abstract}

Italian Microhistory is generally known as being the product of the teachings of Giovanni Levi and Carlo Ginzburg, considered its creators. The figure of Edoardo Grendi, especially outside Europe, is least considered. His role in the creation of the micro-historical proposal is underestimated, although he was perhaps its earlier theorist. Through his attention to the international scientific debate and interest in social sciences, Grendi stood out as an unconventional figure in the academic context of his time. He led to fruitful and controversial discussions. It is possible to place his lessons at the same level as those of Levi and Ginzburg, regardless the separation between social and cultural micro-history within which their work is schematically inserted. These three historians, in fact, were the protagonists of the same battle to establish the possibilities and limits of knowledge of the past. Keywords: morphology; contextualization; microhistory.

\footnotetext{
* Departamento de História, Universidade de Brasília (UnB). Brasília, DF, Brasil. matteogiuli@gmail.com
} 
No panorama acadêmico internacional, sobretudo fora da Europa, a palavra "micro-história", no seu sentido peculiar de origem italiana, é quase automaticamente associada às propostas teóricas e à produção científica de dois historiadores: Giovanni Levi e, ainda mais, Carlo Ginzburg. O enorme sucesso editorial dos seus trabalhos - sobretudo, dos livros Il formaggio e i vermi de Ginzburg (1976) e L'eredità immateriale de Levi (1985), traduzidos no mundo inteiro e lidos também por um público não especialista - explica e em parte justifica esse reconhecimento.

Muito menos extensa, ao contrário, é a difusão dos escritos de Edoardo Grendi, que envolveu apenas uma mínima parte deles. Isso é verdade também com respeito ao contexto acadêmico brasileiro, e mais geralmente sul-americano, onde as propostas da micro-história italiana foram aliás recebidas, não poucas vezes, pela mediação linguística, intelectual e interpretativa da historiografia francesa, espanhola e estadunidense. É suficiente observar as referências bibliográficas de vários textos sobre a micro-história produzidos por especialistas e estudiosos latino-americanos para notar essa situação: além de alguns casos específicos, a disparidade de tratamento reservada aos trabalhos de Levi e Ginzburg, por um lado, e de Grendi, por outro, se revela evidente. A produção científica deste último - numerosa e diversificada do ponto de vista temático (Raggio, 2000) - permanece muito pouco conhecida ou, na melhor das hipóteses, subestimada.

Isso ocorre também quando o papel de Grendi dentro da micro-história italiana é relembrado, pois as referências são quase sempre sucintas e superficiais, as citações são feitas de forma insatisfatória e as alusões se mantêm indiretas (Castro, 1997; Pesavento, 2004; Mendonça, 2008; Cardozo, 2010; Silveira, 2010; Coutinho, 2011; Man, 2013; Ciro, 2016). Emblemático disso é o livro de sucesso que Ronaldo Vainfas publicou em 2002, sobre "os protagonistas anônimos da história”, onde há, além de algumas considerações discutíveis e imprecisas ao tratar da gênese da micro-história, ${ }^{1}$ uma evidente subestimação da contribuição de Grendi, resumida em apenas duas páginas que praticamente não dizem nada sobre as suas propostas teóricas e metodológicas (Vainfas, 2002, p.68-75, 105-116, 152).

As exceções para com essa situação são poucas, mesmo se notáveis: os trabalhos de Carlos Antonio Aguirre Rojas, os quais têm também o mérito de ressaltar as diferenças entre a simples "microhistoria local" mexicana, proposta por Luis González y González, e a "microhistoria de escala” italiana, mais elaborada e "cosmopolita" (Aguirre Rojas, 2003; 2012, p.50-91); a coletânea mexicana Ensayos sobre microhistoria, onde são reeditados os artigos do dossiê $L a$ 
microhistoria en la encrucijada da revista argentina Prohistoria (Barriera, 2002, p.7-59); a coletânea brasileira Exercícios de micro-história, que apresenta a primeira tradução portuguesa de dois textos fundamentais de Grendi, ou seja, Microanálise e história social e Paradoxos da história contemporânea (Almeida; Oliveira, 2009, p.19-49); e, ainda mais, alguns importantes trabalhos de Henrique Espada Lima, capazes de destacar em detalhe a influência exercida pela história social britânica e pela antropologia econômica sobre o pensamento de Grendi (Lima, 2004; 2006, p.153-223).

Essas contribuições são sem dúvida significativas, mas não eliminam o evidente desequilíbrio que existe, no contexto acadêmico sul-americano e ainda mais brasileiro, entre a difusão e o conhecimento das obras de Ginzburg e Levi, por um lado, e de Grendi, por outro. Trata-se de uma situação bastante paradoxal, pois este último foi, no mesmo nível dos outros dois, o pai fundador da micro-história italiana; e talvez, em certa medida, seu mais precoce teorizador.

Seguramente, a linguagem difícil usada por Grendi - pouco "palatável”, segundo ele mesmo (Tigrino, 2011) - pode ter dificultado a tradução dos seus trabalhos e prejudicado a sua difusão; ${ }^{2}$ a falta de entrevistas públicas onde ele pudesse falar de sua trajetória pessoal, explicar seus métodos de pesquisa e esclarecer suas propostas, assim como fizeram muitas vezes Ginzburg e Levi, com certeza não ajudou a melhorar essa situação; a atenção peculiar que ele dedicou à história local - nomeadamente, sobre a República de Gênova, um dos Estados regionais da Itália do Antigo Regime - pode ter, da mesma forma, limitado a recepção da sua produção em termos de representatividade; e, com certeza, sua morte precoce, ocorrida em 1999, aos 67 anos, interrompeu antecipadamente seu percurso de pesquisa, impedindo-o de aperfeiçoar suas exigentes reflexões teóricas.

O presente artigo, portanto, pretende reconstruir, da forma mais completa possível, o perfil profissional, a proposta metodológica e a produção científica desse historiador não convencional, analisando as modalidades pelas quais sua lição foi acolhida e considerada na Itália e no exterior. O objetivo não é o de fazer uma apresentação apologética de seu trabalho de historiador, um elenco cronológico de seus resultados ou uma homenagem retrospectiva de suas intuições heurísticas (baseadas sobretudo - como veremos - na morfologia social e na contextualização topográfica). Trata-se - isso sim - de reconhecer o papel que lhe pertence no contexto da proposta micro-histórica e da sua problematização, assim como resgatá-lo, pelo menos em parte, da posição de marginalidade em 
que foi geralmente deixado, sobretudo fora da Europa, com respeito a historiadores consagrados como Levi e Ginzburg.

Analisar o que Grendi produziu quando "fez história" - parafraseando a celebre pergunta de Michel de Certeau (Certeau, 1975, p.63-65) - pode ser, em última análise, também um modo de amarrar os fios com a microanálise histórica das origens, aquela nascida na Itália dos anos 1970, pela qual muitos historiadores continuam sendo fascinados, e sobre cujas possibilidades metodológicas e epistemológicas continuam, amiúde polemicamente, questionando-se (Sandoica, 1995; Allegra, 2011; Pons; Serna, 2000; 2004; Andrade, 2011; Trivellato, 2011; De Vito, 2015; Lima, 2015).

\section{As CIÊNCIAS SOCIAIS APLICADAS À HISTÓRIA}

A sensibilidade historiográfica de Edoardo Grendi foi sempre marcada por um forte interesse pelas ciências sociais e pelo debate teórico-metodológico internacional. Um momento crucial na formação dessa atitude foi, com certeza, a experiência que ele teve como research student na London School of Economics, entre 1958 e 1960, quando trabalhou sobre a história do movimento operário inglês. Para a realização do seu projeto de pesquisa, além da orientação de Ralph Miliband, naqueles anos autor de alguns estudos notáveis sobre o trabalhismo britânico, Grendi beneficiou-se da colaboração de Eric Hobsbawm, interessado, sobretudo, na análise dos aspectos sociais e culturais do processo de industrialização (Miliband, 1961; Hobsbawm, 1964). Foi um verdadeiro "banho de ciências sociais", que o levou à redação de alguns artigos consagrados ao cartismo e ao socialismo fabiano, publicados em várias revistas italianas, assim como à edição, em 1964, do seu primeiro livro, L'avvento del laburismo. Il movimento operaio inglese dal 1880 al 1920, construído com base em um "diálogo denso com a sociologia" (Lima, 2006, p.154-163; Tigrino, 2011; Raggio, 2013).

Este último foi um trabalho inovador por muitos aspectos, pois visava superar os debates políticos e ideológicos ainda bem vivos no contexto universitário italiano, de inspiração marxista ou liberal, que Grendi conhecia bastante por ter-se formado sobre o idealismo estético de Benedetto Croce (Palumbo, 2004, p.2). O objetivo desse livro sobre o trabalhismo inglês era justamente diferente, pois se interessava pelo estudo das variedades "funcionais e culturais" do movimento operário, reconstruídas por meio de uma abordagem prosopográfica e geográfica from below, ou seja, a partir de baixo (Grendi, 1964, p.24-30). Grendi, nesse sentido, queria evitar qualquer leitura mecanicamente 
positivista do proletariado inglês, propondo uma interpretação original, baseada em algumas características que se tornariam típicas das suas pesquisas seguintes: a recusa do uso apriorístico de critérios hierárquicos de relevância, a integração da disciplina histórica com outras ciências sociais, a importância metodológica atribuída à variação da escala de observação, a vontade de reconstruir a morfologia dos comportamentos sociais dentro do seu espaço material (uma abordagem topográfica) e, de maneira ainda mais peculiar, "a vocação à contextualidade” (Wickham, 2002; Raggio; Torre, 2004, p.5-38).

Os trabalhos de Edward P. Thompson sobre a formação da classe operária inglesa - eles também - representaram um ponto de referência constante para a construção dessa perspectiva metodológica, mesmo se Grendi considerava as suas análises descontextualizadas e excessivamente ideológicas, porque baseadas em uma interpretação marxista da sociedade. A resenha crítica que ele publicou em 1970 na Rivista Storica Italiana sobre o livro The Making of the English Working Class é ilustrativa nesse sentido: de acordo com Grendi, a "economia moral" proposta por Thompson não representava uma rede de solidariedades e reciprocidades, mas apenas uma "economia política socialista"; o mesmo conceito de "classe", portanto, permanecia impróprio para explicar a pluralidade das lógicas dos trabalhadores em uma perspectiva dinâmica, ao ponto de ser considerado melhor substituí-lo com o conceito de "grupo social” (Lima, 2006, p.163-173). É exatamente por essas diferenças que Grendi quis sempre manter certa distância dos trabalhos de Thompson, bastante influenciados pelo seu comprometimento político nas fileiras do Communist Party britânico e, em seguida, dentro da nova esquerda anti-stalinista e pacifista (Thompson, 1963; Grendi, 1994a).

De acordo com Grendi, a organização do proletariado não era apenas a expressão de uma "relação salarial", mas também o resultado de uma "produção socializada", cujos membros deviam ser estudados como homens, além de serem ativistas políticos: a história do trabalhismo devia ser, sobretudo, a história dos trabalhadores e dos trabalhistas. Uma abordagem heurística desse tipo podia permitir, na perspectiva de Grendi, a reconstrução de tipologias fortemente contextualizadas, ou seja, "individualmente, regionalmente, ocupacionalmente caracterizadas" (Grendi, 1972a; Berta, 2002). A história do movimento operário inglês, nessa ótica, tinha de se basear na análise sociológica e geográfica das cidades e dos lugares onde o trabalhismo se havia manifestado com mais força (Londres, Sheffield, Birmingham, Manchester). Era preciso prestar atenção nas dimensões locais para a compreensão da origem 
desse movimento, assim como tinham demonstrado as reflexões de Asa Briggs sobre o cartismo (Briggs, 1959).

Grendi utilizou essa perspectiva metodológica também para trabalhar sobre o proletariado urbano na Itália do século XIX, baseando-se em uma intensa pesquisa arquivística, relacionada com a realidade regional da Ligúria. Nesse sentido ele publicou, por exemplo, alguns artigos sobre as relações entre as organizações sociais do mundo popular e as formas de solidariedade da burguesia, reconstruídas por meio da análise das sociedades mutualistas e das companhias profissionais; sobre a configuração da cidade industrial, destacando a importância crescente das atividades exercidas pelos carregadores e bagageiros em Gênova; sobre os motins insurrecionais de meados do século, interpretados em uma acessão polêmica com respeito à historiografia "ressurgimental" mais tradicional; sobre a difusão das confrarias laicas, analisada por meio de uma perspectiva de baixo, de tipo sociológico e geográfico, largamente influenciada pelos trabalhos de Maurice Halbwachs e Gabriel Le Bras. Em todos esses trabalhos, a atenção pela morfologia das relações sociais representou o ponto de partida constante das suas reflexões (Palumbo, 2004, p.5-10; Tigrino, 2011).

Outro livro inovador de Grendi apareceu em 1973, com o título Introduzione alla storia moderna della Repubblica di Genova, apresentando-se como uma contribuição crítica - não institucional - do ensino tradicional da história nas universidades. O texto evidenciava problemas peculiares de método e de pesquisa, prestando forte atenção à descrição e ao comentário da documentação utilizada. Esta era formada por fontes tiradas de arquivos periféricos e privados, as únicas que, de acordo com Grendi, podiam permitir um trabalho de reconstrução histórica das práticas comunitárias locais e dos relativos mecanismos sociais (Grendi, 1973, p.42-43; Raggio, 1999). Mesmo nesse livro, a vontade de instaurar um verdadeiro diálogo com as outras ciências sociais foi clara (sobretudo com a economia, a demografia e a etnologia), seguindo, a esse respeito, a lição proposta pela Escola dos Annales, em particular pelas pesquisas que Emmanuel Le Roy Ladurie estava conduzindo sobre a Languedoque e o povoado de Montaillou (Le Roy Ladurie, 1975; Burke, 1990).

O estudo - mesmo quantitativo - das fontes fiscais e militares, dos recenseamentos e dos registros paroquiais permitiu a Grendi a reprodução de dados estatísticos úteis para a compreensão da estrutura demográfica e das atividades econômicas dos habitantes de Gênova e da Ligúria na Idade Moderna. Ao mesmo tempo, seguindo em particular os trabalhos antropológicos de Bronislaw Malinowski, Alfred Kroeber, Raymond Firth e Fredrik Barth, ele 
destacou a importância epistemológica de uma análise dinâmica das relações entre grupos sociais e espaço físico, por meio da qual podia evidenciar-se a existência de "trocas e hierarquias mais ou menos intensas" entre comunidades rurais e mercados centrais (Barth, 1981, p.14-75; Rosental, 1996; Raggio; Torre, 2004, p.5-38). De tudo isso decorreu uma interpretação generativa da organização social do Antigo Regime, estudada nas suas características morfológicas e topográficas, com respeito às quais um papel estratégico era desempenhado pelas famílias e pelos parentescos locais (Grendi, 1973, p.213; Raggio, 1990, p.39-62, 152-157; Gribaudi, 1998, p.5-40). O modelo proposto por Grendi, afinal, rompia com a historiografia tradicional de tipo político-institucional; era um modelo em que o diálogo com a antropologia assumiu, cada vez mais, relevância estratégica, até virar o fulcro no qual ele baseou a sua proposta de microanálise histórica.

\section{OS LABORATÓRIOS DA MICROANÁLISE:}

\section{QUADERNI STORICI E MICROSTORIE}

Grendi entrou no comitê de redação de Quaderni storici em 1970, oferecendo um estímulo inovador ao debate historiográfico dessa revista. Com ele havia também Carlo Ginzburg, que naquela época já publicara seu trabalho sobre os "andarilhos do bem" e estava ainda conduzindo as pesquisas sobre as vicissitudes do moleiro Menocchio, em seguida imortalizadas no livro Il formaggio e i vermi (Ginzburg, 1966; 1976; Banti, 1991; Caracciolo, 1999). Desde o começo, as discussões sobre qual linha editorial seguir foram muito animadas, transformando a revista em verdadeiro laboratório coletivo historiográfico, onde se podia propor, avaliar e revisar materiais, teorias e reflexões sobre vários temas de pesquisa, novos ou tradicionais. De acordo com as mais recentes tendências científicas, o conselho editorial decidiu ocupar-se prevalentemente de história social, ou seja, do "estudo das relações entre pessoas e grupos" (Caracciolo, 1999, p.24). Essa escolha foi seguramente influenciada pelos propósitos de Grendi, interessado em trabalhos baseados em exegese aguda das fontes e em reconstrução analítica de "fragmentos de vida" e "ações individuais" (Caracciolo, 1999, p.21).

O modelo de referência era constituído pelas reflexões de Karl Polanyi sobre as consequências sociais e culturais das leis do mercado nas transações econômicas, reflexões com as quais Grendi tinha uma "concordância substancial", como demonstrou na resenha do livro The Great Transformation, 
publicada em 1976 pela Rivista Storica Italiana (Pons; Serna, 2002; Lima, 2006, p.174-187). Do estudioso húngaro foram publicados, mais ou menos na mesma época, alguns textos de antropologia econômica nos quais encontra-se o termo "microanálise histórica”, citado por Grendi e Levi (Grendi, 1972b; 1978; Ginzburg, 1994; Raggio; Torre, 2004, p.5-38; Raggio, 2013). Do ponto de vista lexical, contudo, a palavra "micro-história" apareceu pela primeira vez em 1978, no título de um dossiê organizado por Carlo Poni para Quaderni storici (Poni, 1978).

No ano anterior, na mesma revista, Grendi havia publicado o artigo "Micro-analisi e storia sociale", no qual sugerira uma redução da escala analítica de observação dos comportamentos sociais - o prefixo "micro" refere-se, metaforicamente, ao uso do microscópio (Grendi, 1977). Esse artigo, quase um manifesto da proposta micro-histórica italiana, recomendava um tipo de pesquisa relacionado ao estudo de espaços territoriais e grupos humanos pequenos, tais como as comunidades, as cidades e as corporações profissionais. Sobretudo, nele, Grendi propôs seu mais célebre paradigma, baseado no oximoro "excepcional normal": refletindo sobre o uso das fontes históricas como "testemunhos indiretos", ele evidenciou que qualquer documento aparentemente excepcional pode resultar, na realidade, "excepcionalmente normal" e, portanto, ser "revelador", fornecendo assim as chaves de leitura para decodificar o que ficaria escondido se analisado apenas do ponto de vista da repetitividade dos fatores.

A referência à excepcionalidade de algumas fontes exprimia a ideia de que um comportamento generalizado muitas vezes não é documentado exatamente por sua condição de normalidade, o que pode levar um texto que o registre a ter caráter, ao mesmo tempo, excepcional e normal. Assim, o que à primeira vista aparece insólito, extraordinário ou contingente poderia ser considerado, ao contrário, o sintoma de uma normalidade alternativa, de uma série de regularidades invisíveis aos olhos da historiografia tradicional (Ceccarelli, 2006; Lima, 2006, p.187-199).

O interesse pelas relações entre realidades sociais e dimensões espaciais, pela reconstrução analítica dos contextos e pelos percursos individuais marcou, desde o início, o distanciamento entre a micro-história e a história tradicional de tipo macro (quantitativa e serial), acostumada a usar indicadores simplificados, conceitos abstratos e categorias interpretativas aceitas a priori. O paradigma micro-histórico, ao contrário, criticava as definições preestabelecidas dos objetos de estudo (por exemplo, Estado, mercado, comunidade, família e - como visto com Grendi - classe social), as visões analógicas do 
passado (induzidas a encontrar no passado uma antecipação do presente), as leituras evolutivas baseadas no princípio da continuidade do tempo histórico e os modelos interpretativos de tipo estruturalista e funcionalista (Grendi, 1975; Ginzburg; Poni, 1979; Revel, 1994; Levi, 1996).

Uma das ideias mais importantes, nesse sentido, foi aquela de verificação empírica das propostas teóricas, relacionada a alguns problemas epistemológicos fundamentais, tais como o significado de prova na pesquisa histórica e a reconstrução genética da documentação. A produção desta última tinha de ser interpretada em sentido sociológico e, subsequentemente, contextualizada, pois as fontes arquivísticas representavam, na perspectiva microanalítica, o resultado da atividade institucional de transcrição e certificação das práticas sociais. Era o único método concebido para reconstruir a maneira pela qual os homens do passado percebiam, praticavam e exprimiam a própria realidade.

No âmbito da revista Quaderni storici, além de continuar publicando os próprios trabalhos sobre a República de Gênova, Grendi ocupou-se da edição de alguns dossiês temáticos sobre as estruturas familiares no Antigo Regime (com Giovanni Levi e Gérard Delille), sobre os sistemas assistenciais locais e sobre o uso das fontes criminais dentro da história social (Palumbo, 2004, p.10-18). Isso é muito significativo, pois no curso dos anos os interesses de Grendi moveram-se cada vez mais para as crônicas locais, os processos judiciais e os conflitos jurisdicionais, cuja documentação ele considerava útil para a "reconstrução da cultura através da exploração das práticas sociais" e capaz, ao mesmo tempo, de explicitar as "formas de ação" dos indivíduos (Grendi, 1986a; Grendi, 1994b).

Tratava-se, também, de uma estratégia epistemológica para refletir sobre o relacionamento entre duas tradições jurídicas diferentes: por um lado, a "lei comunitária", que "explicava, em particular, os modos de solução dos conflitos e, em geral, o controle social informal"; por outro, a "lei do Estado", que "postulava, para seu exercício, uma aculturação radical dos cidadãos” (Grendi, 1987a; Grendi, 1990). Nesse sentido, de acordo com Grendi, as práticas sociais interagiam com os poderes formais, criando um discurso político de legitimação jurídica.

As propostas (e as provocações) da micro-história foram recebidas, sobretudo no começo, com ceticismo e também hostilidade pelo mundo acadêmico italiano, onde fazer história ainda significava trabalhar sobre os grandes acontecimentos políticos e econômicos, de forma muitas vezes conotada ideologicamente (Casanova, 2001; Gribaudi, 2011). Nesse contexto, o interesse do 
conselho editorial de Quaderni storici pela antropologia e pelas outras ciências sociais era julgado como algo extravagante.

Contudo, as reflexões micro-históricas nunca se cristalizaram em uma verdadeira escola. Os interesses temáticos permaneceram claramente distintos, levando a um progressivo distanciamento entre uma micro-história de tipo cultural, baseada nos trabalhos de Ginzburg, e uma de tipo social, representada pelas pesquisas de Grendi e Levi (Banti, 1991; Levi, 1992; Ginzburg, 1994; Grendi, 1994b; Cerutti, 2008). Essa evolução do paradigma originário - talvez o produto de um equívoco interpretativo, enfatizado pela recepção estrangeira (Scott, 1989; Zemon Davis, 1990; Pons; Serna, 1993; Pomata, 2000; Aguirre Rojas, 2003; Magnússon, 2006) - foi ligada à reação crítica para com as novas orientações das ciências sociais, em particular contra o relativismo da história interpretativa, afetada pela antropologia simbólica de Clifford Geertz; um tipo de história que, de acordo com Grendi e Levi, considerava em termos autorreferenciais o senso das práticas sociais, propunha casos de estudo não significativos do ponto de vista epistemológico e, sobretudo, ignorava o problema da contextualização das fontes, que não deviam ser concebidas como uma simples "concreção substitutiva" da realidade (Levi, 1985a; Grendi, 1986b).

Globalmente, os dossiês propostos por Quaderni storici manifestaram o que, para Grendi, era "o caráter coletivo da proposta historiográfica da microanálise na Itália” (Grendi, 1994b). Os artigos publicados representavam o produto de uma correspondência redacional densa entre organizadores e autores, de uma série exasperada de leituras e releituras, confrontações e discussões, críticas e correções; um verdadeiro enfrentamento entre proposta programática e resultados concretos, entre metodologia e trabalho de pesquisa.

A mesma atitude dialética foi utilizada no âmbito da coleção Microstorie, inaugurada em 1981 pela editora Einaudi de Turim, sob a direção de Ginzburg e Levi, e com a colaboração de Simona Cerutti. Ativa até 1991, nela foram publicados 21 livros entre originais italianos (por exemplo, L'eredità immateriale de Levi, em 1985) e traduções estrangeiras (por exemplo, a edição italiana, em 1984, do famoso livro The Return of Martin Guerre, de Natalie Zemon Davis). O papel de Grendi nessa coleção também foi importante. Foi ele, de fato, quem se ocupou da publicação dos principais ensaios de Edward P. Thompson sobre a "cultura plebeia" inglesa, retomando assim, com esse historiador, um diálogo a distância que nos anos precedentes não apenas tinha-se resolvido em uma série de críticas ao seu evidente marxismo, mas também em uma apreciação sincera pelo livro Whigs and Hunters e, mais especificamente, 
por seu interesse pela human agency (Thompson, 1981; Palumbo 2004, p.1314; Lima, 2004).

Microstorie publicava monografias densas sobre temas circunscritos, nas quais o raciocínio teórico era plenamente explicitado. O conselho editorial queria propor uma verificação concreta dos materiais de análise, cruzando dimensões, personagens e pontos de vista. Não se tratava apenas de contar a história dos pequenos e dos excluídos, mas de reconstruir, sobretudo, acontecimentos, situações e trajetórias individuais que podiam assumir uma conotação inesperada, permitindo a descoberta de novas categorias interpretativas, novos contextos casuais e novos terrenos de indagação.

A atitude experimental dessas monografias, baseadas na pesquisa arquivística e na confrontação com a historiografia internacional, foi seu mais evidente denominador comum; ao contrário, do ponto de vista temático e da periodização histórica, as diferenças apareceram com mais força. Isso, afinal, refletia coerentemente a lição maior da proposta micro-histórica italiana: aquela de enfrentar a análise de assuntos heterogêneos por meio de instrumentos metodológicos comuns, baseados na redução da escala de observação e no uso intensivo da documentação disponível, além das dimensões e da qualidade intrínseca do objeto estudado (Schulze, 1988; Revel, 1989; Levi, 1992; Lepetit, 1996; Peltonen, 2001; Lima, 2012).

\section{Os MAIORES Trabalhos SOBRE GÊNOVA}

O percurso editorial de Microstorie concluiu-se em 1993, paralelamente à publicação de um livro de Grendi - Il Cervo e la repubblica - que saiu à luz quando essa coleção já havia sido absorvida pela série Paperbacks. O livro propunha a análise intensiva de um povoado da República de Gênova (Cervo mesmo, $O$ Çervo no dialeto lígure), que devia representar, nas intenções do autor, um modelo válido para o estudo das várias comunidades desse Estado: “o contencioso interno provocado pela metrópole é idêntico" - explicava Grendi - e "as estruturas associativas e políticas conectadas com as formas de ocupação do espaço são análogas” (Grendi, 1993a, p.195-199). Um livro importante pela pesquisa arquivística sobre a qual era centrado, mas de maneira alguma simples, nem de compreensibilidade imediata, também pela falta de citações bibliográficas suficientes.

Nele se evidenciava a ambiguidade das relações entre Gênova e Cervo, cujos elementos de contraste eram causados pelas ambições locais, dentro de uma comunidade onde o poder era disputado entre várias agregações parentais 
(Lima, 2006, p.199-221). Centro e periferia, nesse sentido, representavam duas categorias interpretativas que não podiam ser aceitas a priori, mas deviam ser desconstruídas, contextualizadas e reconstruídas. Era um modo para compreender o sentido cultural do relacionamento entre "conflitos locais" e "idiomas políticos", frente à convicção de "que o problema da construção histórica" não podia reduzir-se a "uma dinâmica de forças a ser tratada metaforicamente" (Grendi, 1993a, p.VII-XVI; Radeff, 2007).

Grendi prestou grande atenção à análise do direito possessório, ao exercício da posse como "produto da territorialidade", cujas manifestações rituais podiam ser analisadas em uma relação estrita com as dinâmicas de ocupação do espaço físico. Ao centro das suas reflexões estavam as ações - individuais ou coletivas - que correspondiam a um sistema de valores culturais específicos e que, portanto, resultavam compreensíveis somente se contextualizadas. Eram temas já enfrentados precedentemente, em artigo que fez escola, publicado por Quaderni storici em 1986, a respeito da conflitualidade jurisdicional entre Mioglia e Sassello, duas comunidades do Apenino lígure (Grendi, 1986a); temas sobre os quais, na mesma época, Grendi estava dialogando com Levi e com alguns dos mais brilhantes representantes da segunda geração de micro-historiadores italianos, ou seja, Osvaldo Raggio e Angelo Torre (Torre, 1983, p.45-52; Levi, 1985b, p.151-226; Raggio, 1990, p.IX-XXVI).

A conflitualidade política, reconstruída por meio da documentação judiciária, tinha sido objeto central também de Lettere Orbe, livro publicado em 1989 e baseado na análise da função das cartas anônimas de denúncia para com a gestão das dinâmicas locais de poder. O problema da contextualização permanecia ainda o objeto da pesquisa, pois as fontes arquivísticas tinham desvelado uma diferença tipológica entre as cartas vindas de Gênova e aquelas vindas do território rural: quase todas as primeiras eram heterogêneas e não assinadas, enquanto as segundas buscavam a própria legitimação por meio da “coletividade dos signatários" (Grendi, 1989, p.17-26). Estas últimas eram cartas que testemunhavam a existência de uma criminalidade ligada às rivalidades da aristocracia de Gênova e à proteção garantida aos bandidos, refletindo assim a turbulência contínua que caracterizava as comunidades locais, sempre em busca de uma mediação política com o poder da capital. Sobretudo, por meio da análise da assim chamada "cartografia pobre" (ou seja, dos mapas e desenhos dos terrenos disputados, que eram anexados às mesmas cartas), destacava-se uma vez mais a importância epistemológica de distinguir o conceito de "confim" do de "fronteira", pois sua "antinomia" refletia aquela "entre comunidade e Estado" (Grendi, 1989, p.135-139). 
Essa referência constante à história local, de acordo com Grendi, não era absolutamente algo de autorreferencial, mas devia, ao contrário, dialogar com o debate historiográfico internacional; um debate que, com respeito a Gênova e sua República, sem dúvida não faltava, mesmo que ainda permanecesse centrado, sobretudo, nas atividades econômicas da aristocracia local no Antigo Regime e nas suas capacidades de mobilizar o crédito no nível europeu. Tratava-se do "mito do mercador", ou seja, do paradigma do "virtualismo" financeiro genovês, proposto por Fernand Braudel e por seus seguidores em uma ótica macroscópico-quantitativa que, contudo, de acordo com Grendi, não tinha sido capaz de atribuir a importância correta ao verdadeiro contexto sociopolítico daquela República (Braudel, 1979, p.139-151). Os negócios econômicos de Gênova e da sua aristocracia, de fato, eram estritamente ligados à necessidade de resolver, por meio de trocas comerciais e operações financeiras vultosas, uma situação agrícola deficitária, em particular com respeito à produção de trigo. Nessa perspectiva, as atividades dos mercadores genoveses em âmbito internacional podiam ser compreendidas somente mediante referência contextualizada à situação econômica local.

Tais problemas foram analisados em um livro de 1987, La repubblica aristocratica dei genovesi, onde Grendi recolheu alguns ensaios já publicados anteriormente em algumas das principais revistas italianas (em particular, Rivista Storica Italiana e, como sempre, Quaderni storici). Foram consideradas, sobretudo, as relações entre grupos sociais e espaço local, com atenção peculiar aos elementos socioculturais e topográficos da aristocracia local, para cuja compreensão foi imprescindível reconstruir também as formas de emulação existentes, no nível internacional, entre nobreza genovesa e nobreza espanhola (Grendi, 1987b, p.80-95). A República de Gênova, na ótica de Grendi, constituía uma "realidade social e política rica em paradoxos", capaz de estimular uma série de reflexões generalizáveis em forma de modelo. Entre os membros da aristocracia local, obviamente deu-se espaço importante à figura do famoso almirante Andrea Doria, do qual reconstruiu-se a complexa trajetória individual, que o tornou um meio-termo entre um patriota e um tirano (Grendi, 1987b, p.139-172).

Foi o prelúdio de um interesse cada vez mais forte para a biografia histórica, que no contexto da micro-história italiana já havia sido experimentada, por exemplo, pelo livro L'eredità immateriale, de Levi (Levi, 1985c, p.44-82). Nesse sentido, as pesquisas de Grendi culminaram na publicação de um trabalho de "história privada" - a última monografia da sua produção - sobre a família Balbi, uma das mais importantes da aristocracia de Gênova. Uma 
biografia coletiva, então, baseada na análise morfológica das práticas sociais e das experiências culturais dessa família, com o objetivo de propor - neste caso também - um modelo de referência para o estudo da sociedade aristocrática lígure na Idade Moderna (Raggio; Torre, 2004, p.5-38). Apesar da indubitável dimensão internacional dos seus próprios interesses econômicos (detectáveis em Paris, Viena, Madri, Sevilha e Antuérpia), os Balbi jamais haviam interrompido as ligações concretas com a sua cidade, onde tinham continuado a adquirir bens imóveis e a erguer palácios (Grendi, 1997, p.XI-XXIV).

Depois de uma reconstrução precisa dos acontecimentos que os tinham levado até o ápice das atividades comerciais e financeiras da Europa, por meio, sobretudo, da passagem dos investimentos na produção da seda para os asientos espanhóis, Grendi investigou, em uma "perspectiva etnológica", seu estilo de vida, servindo-se de uma série heterogênea de fontes arquivísticas, de tipo público e privado: não apenas registros fiscais, escrituras notariais e atos judiciários, mas até inventários de bibliotecas e de obras de arte - um conjunto documental necessário para reconstruir também a relação de amizade e colaboração com o famoso pintor flamengo Antoon van Dyck, autor de vários retratos dos membros dessa família (Grendi, 1997, p.95-133).

O objetivo era delinear "um perfil civil da aristocracia genovesa percebida como sistema cultural unitário", onde se destacavam, contudo, diferentes experiências individuais e coletivas. Significativo, nessa ótica, é o capitulo conclusivo, dedicado às mulheres do lar Balbi, onde se propõe um quadro original da componente feminina dessa família e do seu papel específico. A análise morfológica de práticas, experiências e comportamentos apresentada nesse livro refletia a proposta metodológica de Grendi, para quem era importante desmentir a tradicional ideia - filha dos trabalhos macro-históricos e das interpretações quantitativas - da incultura dos genoveses, ou seja, da sua cultura exclusivamente mercantil (Grendi, 1997, p.270-301).

\section{A PROPOSTA DIDÁTICA DE UMA NOVA HISTÓRIA LOCAL}

A micro-história italiana não se interessou apenas pela esfera epistemológica e metodológica da pesquisa historiográfica, mas também pelos aspectos didáticos do ensino universitário e da divulgação científica. Nesse sentido, fez uma crítica forte com respeito à corporação acadêmica, à qual atribuía a responsabilidade de ter favorecido e consolidado uma representação unidirecional do tempo histórico, baseada em um discurso teleológico e hierárquico de desenvolvimento diacrônico, geralmente etnocêntrico e eurocêntrico. Era uma 
posição polêmica em relação às sínteses interpretativas de tipo historicista, consideradas como o produto do assim chamado "senso comum historiográfico", que envolvia todos os paradigmas ideológicos, "liberal, marxista ou social-democrata" (Grendi, 1981; Gribaudi, 1996).

Como titular da cátedra de História Moderna na faculdade de Letras e Filosofia da Universidade de Gênova, Grendi foi um dos maiores protagonistas de tais polêmicas, que animaram vários números da revista Quaderni storici entre 1979 e 1981. Ele se dirigiu, sobretudo, contra o uso tradicional do manual didático de base (que não quis empregar nos seus cursos, porque o considerava um instrumento obsoleto), contra o afastamento, no nível acadêmico, entre ensino e atividade de pesquisa, e contra a persistência, epistemologicamente deletéria, de "arquétipos historiográficos perdidos" (Grendi; Villani, 1976; Grendi, 1979; 1986b).

Suas propostas didáticas encontraram eco significativo, a partir de 1989, com a realização do Seminario permanente di Storia Locale, paralelo ao curso institucional e organizado com alguns colegas do Departamento de História Moderna e Contemporânea da Universidade de Gênova. Esse seminário de história local representava, de acordo com Grendi, um importante momento de confronto entre as atividades de ensino e de pesquisa, onde ele podia estimular o envolvimento direto dos alunos na análise das fontes e no debate historiográfico sobre os temas propostos (Tigrino, 2013).

A paixão de Grendi pela história local tinha amadurecido durante sua estada na Inglaterra, onde essa disciplina, desde o pós-guerra, havia encontrado a própria legitimação também no nível acadêmico, sobretudo na Universidade de Leicester. No contexto britânico, a história local era considerada uma alternativa viável à grande história nacional, que nem sempre havia sido capaz de revelar as informações mais importantes para o conhecimento dos povos e dos territórios por eles ocupados. Aqueles que se dedicavam à English Local History, nesse sentido, tinham de pesquisar, sobretudo, sobre os assuntos econômicos, para reconstruírem as atividades pelas quais os homens do passado alcançavam o necessário para sobreviver (Grendi, 1995). Aliás, nessa perspectiva, por meio do impulso de Herbert Finberg, William George Hoskins e Oliver Rackham, dava-se grande importância à abordagem topográfica, baseada na pesquisa no campo (field work) e na "ligação com o espaço físico" (Grendi, 1993b; Barriera, 2002, p.18-24; Torre, 2002).

Tratava-se de uma proposta que Grendi compartilhava e à qual dedicou muito tempo no âmbito do seu seminário genovês. Em jogo não estava apenas um problema de escala de observação, mas também um problema de 
construção de um novo modelo analítico do território, para que as disciplinas mais tradicionais, relacionadas com a história das comunidades, com a história regional ou com a história dos antigos Estados (modelo predominante nas universidades italianas), eram consideradas ultrapassadas. De acordo com Grendi, somente uma abordagem topográfica, assim como proposta pela escola inglesa, podia permitir uma contextualização refinada do território, "identificado precisamente nos seus limites, mas também estudado na variedade dos elementos materiais presentes ao seu interior", por meio do cruzamento entre disciplinas diferentes, tais como a geografia, a arqueologia e a história (Grendi, 1993b; Wickham, 2002; Torre, 2011). O propósito era interpretar o território e seus elementos materiais (por exemplo, seus confins) como o produto de inter-relações sociais e fenômenos culturais, analisando a relativa dialética, baseada em "conflitos vinculados à ativação dos recursos": era a tentativa, tipicamente "grendiana", de relacionar morfologia social e contextualização topográfica (Torre, 1995; Stopani, 2008).

Em tal perspectiva, portanto, o trabalho dos historiadores não tinha que se basear apenas nas fontes escritas, mas também nas materiais, detectáveis na paisagem local e nos relativos elementos: formas de ocupação do espaço, artefatos urbanos e rurais, representações iconográficas e cartográficas - tudo isso podia contribuir para a renovação do padrão da história local, assim como para a integração "entre conhecimento do território e da sociedade territorial, entre história e estudos do território" (Moreno, 1990; Grendi, 1994b; Palumbo, 2004, p.26-28; Tigrino, 2013).

Nesse sentido, nos cursos do Seminario permanente di Storia Locale foram enfrentados e cruzados vários assuntos, com o objetivo de corrigir o "analfabetismo visual” da historiografia tradicional: a genealogia, a história jurisdicional local, a sabedoria agronômica, a arqueologia, o conhecimento das práticas construtivas e o estudo dos produtos artísticos, a não serem considerados apenas no seu aspecto exterior, técnico ou alegórico. Era a história que se tornava ecistica storica, ou seja, "eco-história" (Pierotti, p.61-68), mesmo que Grendi nunca tenha usado esses termos.

As propostas advindas da Universidade de Leicester e reelaboradas no seminário genovês permitiram a Grendi aprofundar suas próprias reflexões, até a publicação, em 1996, do livro Storia di una storia locale, centrado na "experiência lígure”. Um trabalho no qual foram desenvolvidas críticas epistemológicas importantes para com a assim chamada "história pátria", modelo nascido no curso do século XIX e ainda muito em voga na Itália. Grendi apreciava a sua pluralidade de interesses por tipologias documentárias 
heterogêneas (ligadas também à numismática, aos códigos, aos pergaminhos, às ilustrações e aos pequenos objetos de arte e artesanato), assim como a sua liberdade daquelas "hierarquias das relevâncias" que paralisavam o sistema acadêmico italiano. A "história pátria", contudo, tinha o limite de apresentar-se como uma simples disciplina "colecionística e classificatória", alheia ao problema da contextualização da produção documental e à abordagem topográfica proposta pela escola inglesa. Ademais, ela permanecia uma disciplina para historiadores não profissionais, não conseguindo relacionar-se com o mundo universitário italiano, por sua vez fechado aos estímulos externos e ainda insensível diante dos desenvolvimentos possíveis da história local (Grendi, 1993b; 1996; Wickham, 2002; Tigrino, 2013).

Frente a esses obstáculos, para Grendi foi muito mais fácil e espontâneo dialogar com o mundo universitário britânico, ao qual sempre foi ligado por relações de fecunda colaboração científica e didática. Um exemplo disso é representado pelas visitas anuais à Universidade de Nottingham, onde se realizavam várias pesquisas no campo, baseadas na abordagem topográfica com respeito à história local; e exatamente na ocasião de um desses eventos, em 1999, Grendi faleceu imprevisivelmente, vítima de ataque cardíaco, pouco antes de começar uma palestra dedicada à paisagem lígure (Raggio, 2004).

\section{Conclusões}

É quase banal afirmar que Edoardo Grendi tenha ocupado lugar de destaque no contexto acadêmico italiano entre os anos 1970 e 1990, tendo sido um historiador capaz de enquadrar as próprias reflexões epistemológicas no debate científico internacional. Sua sensibilidade para o diálogo interdisciplinar o levou a confrontar-se, também de maneira polêmica, com algumas das maiores figuras da historiografia e das ciências sociais do seu tempo, tais como Edward P. Thompson, Eric Hobsbawm, Natalie Zemon Davis, Karl Polanyi e Clifford Geertz, e também com os estudiosos mais próximos da Escola dos Annales. Isso lhe permitiu unir pesquisa de arquivo e teoria metodológica, oferecendo contribuições que eram "sociológicas, antropológicas e (mais raramente) econômicas, no mesmo momento em que eram históricas" (Wickham, 2002).

Seu trabalho, com certeza, encontrou numerosas vozes discordantes, algumas das quais o acusaram de dedicar-se a uma história local pouco representativa, ou ainda de desinteressar-se excessivamente dos grandes eventos da história política. Muitas propostas associadas ao nome de Grendi marcaram, na Itália, um momento de discussão até provocativo, pois elas se apresentavam 
como um modelo alternativo às impostações historiográficas até então predominantes (em primeiro lugar, aquelas de orientação marxista). De acordo com Osvaldo Raggio e Angelo Torre, "Grendi tentou reconstruir a sociedade e as culturas do passado por meio de óculos inusitados", provocando "um forte efeito de desorientação" e recebendo, consequentemente, mas não sempre justamente, várias críticas e objeções (Raggio; Torre, 2004, p.5-38).

É também verdade que alguns conceitos de base da sua proposta metodológica não foram suficientemente esclarecidos, nem encontraram uma explicação adequada por meio de contribuições específicas. Suas discussões sobre a micro-história ficaram expostas, sobretudo, em textos de caráter teórico e metodológico, mais do que em trabalhos concretos de pesquisa arquivística. Por consequência, o plano propositivo e o plano empírico da sua produção ficaram, muitas vezes, separados, sem mostrarem real influência recíproca em termos de aplicação. Em particular, a sua ideia de abordagem topográfica não conseguiu respeitar os intentos programáticos e terminou sendo empregada em trabalhos de pesquisa tradicional nos arquivos, carecendo de uma atitude verdadeiramente "eco-histórica".

O paradigma do "excepcional normal" também não foi sondado em todas suas possibilidades epistemológicas, a tal ponto que sua interpretação originou vários mal-entendidos. Esse paradigma - que aliás, de acordo com Grendi, "foi sem a menor dúvida superestimado" (Grendi, 1994b; Ceccarelli, 2006) - talvez tivesse sido excessivamente focado no uso das fontes jurisdicionais, sem favorecer uma reflexão aprofundada sobre o problema das séries arquivísticas e sobre a importância da comparação analógica de contextos documentais diferentes.

Globalmente, contudo, a proposta teórica e a produção científica de Grendi merecem um destaque claro no contexto da micro-história italiana e nas reconsiderações que dela continuam sendo efetuadas pela historiografia internacional. O já citado livro que ele escreveu sobre a família Balbi, por exemplo, pode constituir ótimo ponto de partida para tentar utilizar o método microanalítico em perspectiva transnacional e para relacionar a micro-história local (qualitativa e individual) com a macro-história global (quantitativa e serial).

Dentro do atual panorama historiográfico, caracterizado por um verdadeiro global turn, um dos desafios mais promissores do ponto de vista epistemológico é exatamente aquele de enfrentar assuntos de tipo extralocal por meio de microanálises circunscritas. Nesse sentido, a abordagem biográfica, ou também prosopográfica, pode oferecer possibilidades interessantes para 
uma nova global micro-history, permitindo a recolocação de vidas individuais e relações sociais dentro de contextos translocais, de modo a destacar a capacidade de ação das pessoas (agency) e o sincretismo cultural que sempre existiu na história, apesar das barreiras geográficas, linguísticas e religiosas (Trivellato, 2009; Andrade, 2011; Scott; Hébrard, 2012; De Vito, 2015; Lima, 2015).

Trata-se, portanto, de reconstruir verdadeiras biografias micro-históricas em movimento, o que Grendi soube antecipar, pelo menos em certa medida, no livro sobre os Balbi, relacionando a dimensão internacional e aquela local dos interesses econômicos e dos laços culturais dessa família. É nessa mesma lógica de reavaliação dos encontros transculturais na história - os cross-cultural encounters, típicos do communitarian cosmopolitanism de alguns grupos particulares, por exemplo os mercadores, os escravos e os judeus (Trivellato, 2011) - que o método microanalítico pode ter um futuro fecundo frente à volta global do debate historiográfico.

É também por essas razões que o papel de Grendi merece destaque específico no contexto da micro-história italiana e nas suas atuais avaliações internacionais. Analisando retrospectivamente seus trabalhos, é possível ver que eles se colocam no mesmo plano daqueles de Levi e de Ginzburg, para além da separação entre micro-história social e micro-história cultural no âmbito da qual tais historiadores foram apressadamente inseridos. Por meio de instrumentos diferentes, com interesses e sensibilidades diferentes, esses três fundadores da micro-história italiana foram protagonistas da mesma batalha, aquela relativa à "representação da realidade" do passado, ou seja, às possibilidades concretas do conhecimento histórico.

\section{REFERÊNCIAS}

AGUIRRE ROJAS, Carlos Antonio. Invitación a otra microhistoria: la microhistoria italiana. Historica, Lima: Pontificia Universidad Católica del Perú, v.27, n.2, p.283317, 2003. . Micro-história italiana: modo de uso. Londrina: Eduel, 2012.

ALLEGRA, Luciano. Ancora a proposito di micro-macro. In: LANARO, Paola (Org.) Microstoria: a venticinque anni da L'eredità immateriale. Milano: FrancoAngeli, 2011. p.59-68.

ALMEIDA, Carla Maria C. de; OLIVEIRA, Mônica R. de (Org.) Exercícios de micro-história. Rio de Janeiro: Ed. FGV, 2009. 
ANDRADE, Tonio. A Chinese Farmer, Two African Boys, and a Warlord: Toward a Global Microhistory. Journal of World History, Honolulu: University of Hawaii Press, v.21, n.4, p.573-591, 2011.

BANTI, Alberto Mario. Storie e microstorie: l'histoire sociale contemporaine en Italie (1972-1989). Genèses, Paris: Éd. Belin, v.3, n.1, p.134-147, 1991.

BARRIERA, Darío Gabriel (Org.) Ensayos sobre microhistoria. Morelia: Red Utopía, 2002.

BARTH, Fredrik. Process and Form in Social Life: Selected Essays of Fredrik Barth. (Ed. Adam Kuper). v.1. London: Routledge and Kegan, 1981.

BERTA, Giuseppe. Una prospettiva per la storia del movimento operaio: Edoardo Grendi e il laburismo. Quaderni storici, Bologna: il Mulino, v.110, n.2, p.553-561, 2002.

BRAUDEL, Fernand. Civilisation matérielle, économie et capitalisme, $X V^{e}-X V I I I^{e}$ siècle: 3. Le temps du monde. Paris: Armand Colin, 1979.

BRIGGS, Asa (Org.) Chartist Studies. London: Macmillan and Co., 1959.

BURKE, Peter. The French Historical Revolution: The Annales School, 1929-89. Stanford, CA: Stanford University Press, 1990.

CARACCIOLO, Alberto. La prima generazione. Quaderni storici, Bologna: il Mulino, v.100, n.1, p.13-29, 1999.

CARDOZO, José Carlos da S. Reflexões sobre a abordagem macro e micro na História. Mneme. Revista de humanidades, Caicó: Universidade Federal do Rio Grande do Norte (UFRN), v.11, n.28, p.31-46, 2010.

CASANOVA, Cesarina. L'Italia moderna: temi e orientamenti storiografici. Roma: Carocci, 2001.

CASTRO, Hebe. História social. In: CARDOSO, Ciro F.; VAINFAS, Ronaldo (Org.) Domínios da História: ensaios de teoria e metodologia. Rio de Janeiro: Campus, 1997. p.76-96.

CECCARELLI, Alessandro. Contesto e concetto. Alcune riflessioni sulla microstoria. 2006. Disponível em: http://archiviomarini.sp.unipi.it/77/; Acesso em: 11 jan. 2017. CERTEAU, Michel de. L'écriture de l'histoire. Paris: Gallimard, 1975.

CERUTTI, Simona. Histoire pragmatique, ou de la rencontre entre histoire sociale et histoire culturelle. Tracés. Revue de Sciences humaines, Lyon: ENS Éd., v.15, n.2, p.147-168, 2008.

CIRO, Eulalia Hernández. Microhistoria italiana, antropología y archivos judiciales. Historia y Sociedad, Medellín: Universidad Nacional de Colombia, n.30, p.75-104, 2016.

COUTINHO, Sérgio Ricardo. Por uma micro-história pós-metafísica. As possibilidades do agir comunicativo em estudos de "história ao rés-do-chão". Revista de Teoria da História, Goiânia: Universidade Federal de Goiás (UFG), v.5, n.1, p.83-117, 2011. 
DE VITO, Christian G. Verso una microstoria translocale (Micro-spatial history). Quaderni storici, Bologna: il Mulino, v.150, n.3, p.815-833, 2015.

GINZBURG, Carlo. I benandanti: ricerche sulla stregoneria e sui culti agrari tra Cinquecento e Seicento. Torino: Einaudi, 1966.

. Il formaggio e i vermi: il cosmo di un mugnaio del Cinquecento. Torino: Einaudi, 1976.

. Microstoria: due o tre cose che so di lei. Quaderni storici, Bologna: il Mulino, v.86, n.2, p.511-539, 1994.

GINZBURG, Carlo; PONI, Carlo. Il nome e il come: scambio ineguale e mercato storiografico. Quaderni storici, Bologna: il Mulino, v.40, n.1, p.181-190, 1979.

GRENDI, Edoardo (Org.) L'antropologia economica. Torino: Einaudi, 1972b.

. Charles Phythian-Adams e la "local history" inglese. Quaderni storici, Bologna: il Mulino, v.89, n.2, p.559-578, 1995.

. Del senso comune storiografico. Quaderni storici, Bologna: il Mulino, v.41, n.2, p.698-707, 1979.

. E.P. Thompson e la "cultura plebea". Quaderni storici, Bologna: il Mulino, v.85, n.1, p.235-247, 1994a.

. Fonti criminali e storia sociale. Quaderni storici, Bologna: il Mulino, v.66, n.3, p.695-700, 1987a.

. I Balbi: una famiglia genovese fra Spagna e Impero. Torino: Einaudi, 1997.

. Il Cervo e la repubblica: il modello ligure di antico regime. Torino: Einaudi, 1993a.

. Il "Daumardismo": una via senza uscita? Quaderni storici, Bologna: il Mulino, v.29-30, n.2-3, p.729-737, 1975.

. Introduzione alla storia moderna della Repubblica di Genova. Genova: Fratelli Bozzi, 1973.

. L'avvento del laburismo: il movimento operaio inglese dal 1880 al 1920. Milano: Feltrinelli, 1964.

. La pratica dei confini: Mioglia contro Sassello, 1715- 1745. Quaderni storici, Bologna: il Mulino, v.63, n.3, p.811-845, 1986 .

- La repubblica aristocratica dei genovesi: politica, carità e commercio fra Cinque e Seicento. Bologna: il Mulino, 1987b.

. Lettere Orbe: anonimato e poteri nel Seicento genovese. Palermo: Gelka, 1989.

. Micro-analisi e storia sociale. Quaderni storici, Bologna: il Mulino, v.35, n.2, p.506-520, 1977.

. Paradossi della Storia contemporanea. In: BOLOGNA, Sergio (Org.) Dieci interventi sulla storia sociale. Torino: Rosenberg \& Sellier, 1981. p.67-74.

. Polanyi: dall'antropologia economica alla microanalisi storica. Milano: Etas Libri, 1978. 
GRENDI, Edoardo. Ripensare la microstoria? Quaderni storici, Bologna: il Mulino, v.86, n.2, p.539-549, 1994 b.

. Storia di una storia locale: l'esperienza ligure 1792-1992. Venezia: Marsilio, 1996.

. Storia di una storia locale: perché in Liguria (e in Italia) non abbiamo avuto una local history? Quaderni storici, Bologna: il Mulino, v.82, n.1, p.141-197, 1993 b. . Storia sociale e storia interpretativa. Quaderni storici, Bologna: il Mulino, v.61, n.1, p.201-210, 1986b.

. Sulla "storia criminale": risposta a Mario Sbriccoli. Quaderni storici, Bologna: il Mulino, v.73, n.1, p.269-275, 1990.

. Una prospettiva per la storia del movimento operaio. Quaderni storici, Bologna: il Mulino, v.20, n.2, p.597-618, 1972a.

GRENDI, Edoardo; VILLANI, Pasquale. Testi commestibili, o meno. Quaderni storici, Bologna: il Mulino, v.33, n.3, p.1195-1206, 1976.

GRIBAUDI, Maurizio. Échelle, pertinence, configuration. In: REVEL, Jacques (Org.) Jeux d'échelles: la micro-analyse à l'expérience. Paris: Gallimard-Le Seuil, 1996. p.113-140.

. La lunga marcia della microstoria: dalla politica all'estetica? In: LANARO, Paola (Org.) Microstoria: a venticinque anni da L'eredità immateriale. Milano: FrancoAngeli, 2011. p.9-23.

. (Org.) Espaces, Temporalités, Stratifications: exercises sur les réseaux sociaux. Paris: Éditions de l'École des Hautes Études en Sciences Sociales, 1998.

HOBSBAWM, Eric John. Labouring Men: Studies in the History of Labour. London: Weidenfeld and Nicolson, 1964.

LE ROY LADURIE, Emmanuel. Montaillou, village occitan de 1294 à 1324. Paris: Gallimard, 1975.

LEPETIT, Bernard. De l'échelle en histoire. In: REVEL, Jacques (Org.) Jeux d'échelles: la micro-analyse à l'expérience. Paris: Gallimard-Le Seuil, 1996. p.71-94.

LEVI, Giovanni. Centro e periferia di uno stato assoluto: tre saggi su Piemonte e Liguria in età moderna. Torino: Rosenberg \& Sellier, 1985b.

Comportements, ressources, procès: avant la "révolution" de la consommation. In: REVEL, Jacques (Org.) Jeux d'échelles: la micro-analyse à l'expérience. Paris: Gallimard-Le Seuil, 1996. p.185-207.

. I pericoli del geertzismo. Quaderni storici, Bologna: il Mulino, v.58, n.1, p.269-277, 1985a.

L'eredità immateriale: carriera di un esorcista nel Piemonte del Seicento. Torino: Einaudi, 1985c.

. On Microhistory. In: BURKE, Peter (Org.) New Perspectives on Historical Writing. Old Main: Pennsylvania State University Press, 1992. p.93-113. 
LIMA, Henrique E. A micro-história italiana: escalas, indícios e singularidades. Rio de Janeiro: Civilização Brasileira, 2006.

.E. P. Thompson e a micro-história: trocas historiográficas na seara da história social. Esboços, Florianópolis: Universidade Federal de Santa Catarina (UFSC), v.11, n.12, p.53-74, 2004.

. Micro-história. In: CARDOSO, Ciro F.; VAINFAS, Ronaldo (Org.) Novos Domínios da História. Rio de Janeiro: Elsevier, 2012. p.207-223.

. No baú de Augusto Mina: o micro e o global na história do trabalho. Topoi, Rio de Janeiro: Universidade Federal do Rio de Janeiro (UFRJ), v.16, n.31, p.571595, 2015.

MAGNÚSSON, Sigurdur G. Social History as "Sites of Memory?" The Institutionalization of History: Microhistory and the Grand Narrative. Journal of Social History, Oxford: Oxford University Press, v.39, n.3, p.891-913, 2006.

MAN, Ronen. La microhistoria como referente teórico-metodológico. Un recorrido por sus vertientes y debates conceptuales. Historia Actual Online, Cádiz: Asociación de Historia Actual, n.30, p.167-173, 2013.

MENDONÇA, Ligia B. de. Entre leões e caçadores: a micro-história como aporte teórico-metodológico para (na) história da educação brasileira. In: CONGRESSO BRASILEIRO DE HISTÓRIA DA EDUCA囚ÃO, 5., “O Ensino e a Pesquisa em História da Educação”, 2008, Aracaju. p.1-21. Disponível em: http://www.sbhe.org. br/novo/congressos/cbhe5/pdf/706.pdf.

MILIBAND, Ralph. Parliamentary Socialism: A Study in the Politics of Labour. London: George Allen \& Unwin, 1961.

MORENO, Diego. Dal documento al terreno: storia e archeologia dei sistemi agro-silvo-pastorali. Bologna: il Mulino, 1990.

MUIR, Edward. Introduction: Observing Trifles. In: .; RUGGIERO, Guido (Org.) Microhistory and the Lost Peoples of Europe. Baltimore, MD: Johns Hopkins University Press, 1991. p.VII-XXVIII.

PALUMBO, Paolo. Le dialettiche della microstoria. Edoardo Grendi e l'interdisciplinarità nel mestiere dello storico. Balbisei. Ricerche Storiche Genovesi, Genova: Università degli Studi di Genova, n.0, p.1-31, 2004.

PELTONEN, Matti. Clues, Margins, and Monads: the Micro-Macro Link in Historical Research. History and Theory, Middletown, CT: Wiley-Blackwell, n.40, p.347-359, 2001.

PESAVENTO, Sandra J. O corpo e a alma do mundo. A micro-história e a construção do passado. História Unisinos, São Leopoldo, RS: Universidade do Vale do Rio dos Sinos (Unisinos), v.8, n.10, p.179-189, 2004.

PIEROTTI, Piero. Imparare l'ecostoria. Milano: FrancoAngeli, 1999. 
POMATA, Gianna. Telling the Truth about Micro-History: a Memoir (and a Few Reflections). Netveerk for Historieteori og Historiografi, Odense: Syddansk Universitet, n.3, p.28-40, 2000.

PONI, Carlo. Azienda agraria e microstoria. Quaderni storici, Bologna: il Mulino, v.39, n.3, p.801-805, 1978.

PONS, Anaclet; SERNA, Justo. Cómo se escribe la microhistoria: ensayo sobre Carlo Ginzburg. Madrid: Ed. Cátedra, 2000.

. El ojo de la aguja ¿De qué hablamos cuando hablamos de microhistoria? Ayer, Madrid: Asociación de Historia Contemporánea, n.12, p.93-133, 1993.

. Formas de hacer microhistoria. Àgora. Revista de Ciencias Sociales, Valencia: Fundación Centro de Estudios Políticos y Sociales, n.7, p.1-18, 2002.

Nota sobre la microhistoria. ¿No habrá llegado el momento de parar? Pasado y memoria. Revista de Historia Contemporánea, Alicante: Universidad de Alicante, n.3, p.255-263, 2004.

RADEFF, Anne. Centres et périphéries ou centralités et décentralités? In: TORRE, Angelo (Org.) Per vie di terra: movimenti di uomini e di cose nelle società di antico regime. Milano: FrancoAngeli, 2007. p.21-32.

RAGGIO, Osvaldo. Bibliografia degli scritti di Edoardo Grendi. Quaderni storici, Bologna: il Mulino, v.105, n.3, p.823-834, 2000.

Faide e parentele: lo stato genovese visto dalla Fontanabuona. Torino: Einaudi, 1990.

. La storia come pratica. Omaggio a Edoardo Grendi (1932-1999). Quaderni storici, Bologna: il Mulino, v.100, n.1, p.3-10, 1999.

. Microhistorical Approaches to the History of Liguria: From Microanalysis to Local History. Edoardo Grendi’s Achievements. In: BALZARETTI, Ross; PEARCE, Mark; WATKINS, Charles (Org.) Ligurian Landscape: Studies in Archaeology, Geography and History in Memory of Edoardo Grendi. London: Accordia Research Institute, 2004. p.97-104.

. Microstoria e microstorie. 2013. In: ENCICLOPEDIA Italiana di scienze, lettere ed arti. Disponível em: http://www.treccani.it/enciclopedia/microstoria-e-microstorie_(altro)/; Acesso em: 19 jan. 2017.

RAGGIO, Osvaldo; TORRE, Angelo. In altri termini: etnografia e storia di una società di antico regime. Milano: Feltrinelli, 2004.

REVEL, Jacques. L'histoire au ras du sol. In: LEVI, Giovanni. Le Pouvoir au village: histoire d'un exorciste dans le Piémont du XVII e siècle. Paris: Gallimard, 1989. p.I-XXXIII.

. Microanalisi e costruzione del sociale. Quaderni Storici, Bologna: il Mulino, v.86, n.2, p.549-575, 1994. 
ROSENTAL, Paul-André. Construire le "macro" par le "micro": Fredrik Barth et la microstoria. In: REVEL, Jacques (Org.) Jeux d'échelles: la micro-analyse à l'expérience. Paris: Gallimard-Le Seuil, 1996. p.141-159.

SANDOICA, Elena Hernández. Los caminos de la historia: cuestiones de historiografía y método. Madrid: Síntesis, 1995.

SCHULZE, Winfried. Mikrohistorie versus Makrohistorie? Anmerkungen zu einem aktuellen Thema. In: MEIER, Christian; RÜSEN, Jörn (Org.) Theorie der Geschichte: Beiträge zur Historik. 5. Historische Methode. München: Deutscher Taschenbuch Verlag, 1988. p.319-341.

SCOTT, Joan W. History in Crisis? The Others' Side of the Story. The American Historical Review, Oxford: Oxford University Press, v.94, n.3, p.680-692, 1989.

SCOTT, Rebecca J.; HÉBRARD, Jean. Freedom Papers: An Atlantic Odyssey in the Age of Emancipation. Cambridge, MA: Harvard University Press, 2012.

SILVEIRA, Eder da Silva. Estudo de caso e micro-história: distanciamentos, características e aproximações. Revista Eletrônica História em Reflexão, Dourados: Universidade Federal da Grande Dourados (UFGD), v.4, n.8, p.1-10, 2010.

STOPANI, Antonio. La production des frontières: état et communautés en Toscane (XVI ${ }^{-}$-XVIII ${ }^{e}$ siècles). Roma: École française de Rome, 2008.

THOMPSON, Edward P. Società patrizia, cultura plebea: otto saggi di antropologia storica sull'Inghilterra del Settecento. GRENDI, Edoardo (Ed.) Torino: Einaudi, 1981.

The Making of the English Working Class. London: Victor Gollancz, 1963.

TIGRINO, Vittorio. "La vocazione alla contestualità". Ricerca e didattica in Edoardo Grendi (1932-1999). 2011. Disponível em: http://www.stmoderna.it/Memoria/ DettagliMemoria.aspx?id=28; Acesso em: 29 jan. 2017.

. Storia di un Seminario di Storia locale. Edoardo Grendi e il Seminario permanente di Genova (1989- 1999). In: CEVASCO, Roberta (Org.) La natura della montagna: scritti in ricordo di Giuseppina Poggi. Sestri Levante: Oltre Ed., 2013. p.211-232.

TORRE, Angelo. Comunità e località. In: LANARO, Paola (Org.) Microstoria: a venticinque anni da L'eredità immateriale. Milano: FrancoAngeli, 2011. p.25-57.

. Il consumo di devozioni: religione e comunità nelle campagne dell'Ancien Régime. Venezia: Marsilio, 1995.

. La produzione storica dei luoghi. Quaderni storici, Bologna: il Mulino, v.110, n.2, p.443-475, 2002.

. Stato e società nell'Ancien Régime. Torino: Einaudi, 1983.

TRIVELLATO, Francesca. Is There a Future for Italian Microhistory in the Age of Global History? California Italian Studies, Berkeley: University of California, v.2, n.1, p.1-24, 2011. 
TRIVELLATO, Francesca. The Familiarity of Strangers: The Sephardic Diaspora, Livorno, and Cross-Cultural Trade in the Early Modern Period. New Haven, CT: Yale University Press, 2009.

VAINFAS, Ronaldo. Os Protagonistas Anônimos da História: micro-história. Rio de Janeiro: Campus, 2002.

WICKHAM, Chris. Edoardo Grendi e la cultura materiale. Quaderni storici, Bologna: il Mulino, v.110, n.2, p.323-332, 2002.

ZEMON DAVIS, Natalie. The Shapes of Social History. Storia della Storiografia, Pisa-Roma: Fabrizio Serra Ed., v.17, n.1, p.28-35, 1990.

\section{NOTAS}

${ }^{1}$ Vainfas coloca o surgimento da micro-história na década de 1980, relacionando-o quase exclusivamente com a crise da história das mentalidades ("o percurso que vimos de reconstruir da história das mentalidades à história cultural é de suma importância para a localização da gênese da micro-história") e sobrepondo-o, de forma imprecisa, à difusão da coleção Microstorie da editora turinesa Einaudi ("a micro-história - a italiana Microstorie - surgiu na década de 1980 como iniciativa editorial da Einaudi, antes de ser um gênero ou uma corrente historiográfica").

2 "Em Grendi, o desejo fortíssimo de comunicar enfrentava obstáculos de todo gênero que ele mesmo interpunha à comunicação. A dificuldade do seu estilo, no qual anglicismos fresquíssimos misturavam-se a genovesismos de alguns séculos, era legendária ... Mas o eco do seu ensinamento e dos seus escritos, programáticos ou não, foi profundo. Eles contribuíram de maneira decisiva para a elaboração do projeto micro-histórico." Foi Carlo Ginzburg a lembrar isso no seu prefácio ao livro A micro-história italiana de Henrique Espada Lima (LIMA, 2006, p.9-12).

Artigo recebido em 23 de março de 2017. Aprovado em 3 de abril de 2017. 